\title{
Meaningful living, resilience, affective balance, and psychological health problems among Turkish young adults during coronavirus pandemic
}

\author{
Murat Yıldırım $^{1,2} \cdot$ Gökmen Arslan $^{3,4,5}$ (D) Paul T. P. Wong ${ }^{6}$ \\ Accepted: 26 November 2020 / Published online: 6 January 2021 \\ (C) The Author(s), under exclusive licence to Springer Science+Business Media, LLC part of Springer Nature 2021
}

\begin{abstract}
The present study sought to investigate the mediating effect of the affective balance and resilience on the association between meaningful living and psychological health problems among Turkish young adults in the context of COVID-19. The participants were 359 Turkish young adults, comprising of primarily female (68.2\%), and their age ranged between 18 to 43 (age $M=20.67$, $S D=3.62$ ). Findings from this study indicated that meaningful living had a positive predictive effect on resilience and positive affect, as well as a negative predicative on psychological health challenges and negative affect. Resilience and affective balance also mediated the effect of meaningful living on psychological health of young adults. These results suggest that resilience and affective balance are important aspects of meaning-focused preventions and interventions designed to build up resilience, positive affectivity, and psychological health.
\end{abstract}

Keywords Meaningful living $\cdot$ Resilience $\cdot$ Affective balance $\cdot$ Psychological health $\cdot$ COVID-19 Existential positive psychology

On March 11, 2020, the World Health Organization (WHO) declared COVID-19 as a pandemic caused by a novel coronavirus SARS-CoV2 (WHO 2020a). Within few months, the world had been adversely affected by the rapid escalation of the virus, exponential growth in the number of new cases, and fatality rate of COVID-19 (Wu et al. 2020; Zhou et al. 2020). According to daily statistics published by Johns Hopkins University, as of 9 May 2020, there have been more than 3.9 million confirmed COVID-19 cases worldwide and more than 275,000 deaths, affecting 187 countries and territories (Center for Systems Science and Engineering 2020). Continuous

\section{Gökmen Arslan}

gkmnarslan@gmail.com.tr

$1 \quad$ Ağrı İbrahim Çeçen University, Ağrı, Turkey

2 University of Liecester, Liecester, UK

3 Department of Psychological Counseling and Guidance, Faculty of Education, Mehmet Akif Ersoy University in Burdur, Burdur, Turkey

4 Burdur Mehmet Akif Ersoy University, Burdur, Turkey

5 International Network on Personal Meaning, Toronto, Ontario, Canada

6 Trent University, Peterborough, ON, Canada dangers from COVID-19 and disruptions of everyday life have undoubtedly caused serious psychosocial consequences. During the outbreak, prevalence of mental health problems has increased substantially, especially among those with preexisting psychological conditions, and further worsening their daily functioning and cognition (Yang et al. 2020). Maintaining psychological health can be difficult with a high level of psychological distress (e.g., anxiety and depression; de Cates et al. 2015); therefore, protecting individuals mental health and psychosocial wellbeing is just as important as maintaining physical health during the pandemic (WHO 2020b).

Research has shown that prior to the pandemic, the resources of individuals (such as positive emotions, positive traits and social support, and meaning in life) can protect their mental health and reduce the risk of diseases (Kobau et al. 2011; Steger et al. 2009b; Wong 2017; Yildirim and Arslan 2020). However, in the era of COVID-19, life has become more complicated, when people are bombarded daily by news of the rising death toll, new cases, and unemployment numbers. Our way of life has been fundamentally changed with the new rules of social distancing, lockdown, and mask-wearing. People confronted with an existential threat of biblical proportions are more prone to believing that life is full of suffering and hardship, a basic tenet from the existential positive 
psychology perspective (PP 2.0; Wong 2010a). There are several reasons why the PP 2.0 offers a more appropriate framework in times like these (Wong 2019). Firstly, PP 2.0 is based on integrating the existential tradition of suffering (Frankl 1985) and positive psychology of wellbeing and flourishing (Seligman 2011); thus, it is better equipped to address issues of existential suffering during COVID-19. Secondly, PP 2.0 does not focus only on positive affect; it emphasizes the need to balance between positive and negative emotion in order to achieve optimal wellbeing (Wong 2011); thus, it does not matter how much negative emotions one feels, as long as one is able to achieve a positive affective balance, typically in the form of mature happiness which can co-exist with negative situations and emotions (Wong and Bowers 2018). It is appropriate that the present study make affective balance a variable. Thirdly, PP 2.0 advocates the need to embrace and transform suffering through meaning as the foundation for personal growth in resilience and psychological functioning. Therefore, resilience depends on not just signature character strengths, but also on the courage and mental toughness to face and endure suffering. Fourthly, the coronavirus is not simply a single traumatic event, but a prolonged, "highly stressful and challenging life-altering event" (Tedeschi et al. 2018 , p. 4). In sum, the challenges that occurred during COVID-19 support the basic tenets of PP 2.0 that (a) life is full of suffering and hardships, and (b) sustainable wellbeing is based on overcoming or transforming suffering through meaning. Using an existential positive psychology perspective, this study therefore aims to examine the mediating effect of the affective balance and resilience on the relationship between meaningful living and psychological health problems during COVID-19 pandemic.

\section{Meaningful Living and Psychological Health}

Meaningful living simply means to exercise one's volition to find meaning and purpose in life and live accordingly. The motivation to search for meaning can be awakened by reading a book, such as Frankl's Man's Search for Meaning (1985), or going thorough suffering which demands an answer to such existential questions as "Is there any meaning in suffering?" "What is the point of living, since life is so hard?" People are more likely to engage in the quest for meaning during COVID-19, because their assumptive world is shattered when what they used to depends on for their happiness and selfidentity are taken away from them. Such traumatic events naturally create an existential crisis, which may serve as an opportunity of spiritual awakening. They may become disillusioned with shallowness or meaninglessness of living purely in the materialistic realm and feel an inner discomfort from the existential vacuum. This realization may provide the impetus for them to search for their real self and true purpose in life
This fundamental shift from horizontal living in a consumeristic society, to the spiritual or transcendental reality of serving someone or something greater than themselves is the beginning of living a meaningful life world (Batthyany and RussoNetzer 2014; Frankl 1985; Hicks and Routledge 2013; Wong 2012a, 2016a). These publications provide a great deal of empirical evidence that having a sense of meaning in life can play a key role to sustain and maintain psychological health even in times of adversity. Meaning in life is often defined as having coherence, purpose, and significance (Martela and Steger 2016). However, Wong (2010b) favours a 4-factor definition in terms of Purpose, Understanding (coherence), Responsibility, and Enjoyment (a sense of fulfilment or significance); the PURE model as an acronym. Wong emphasizes the importance of responsibility in meaningful living, because during an existential crisis, there has to be a point in time when an individual is awakened to the need to make a deliberate choice to change the direction of their lives in the view of adversity and shattered dreams. According to Wong (2012a) a meaningful life is characterised by a balanced life resulting from the dynamic interaction between positives and negatives, as well as managing a balance among different sources of meaning, between achievement and accepting one's limitation (Wong 1998). The key to meaningful living or living a meaningful life is one's ability to navigate between opposite forces to achieve an optimal balance.

Psychological distress is characterized as a general, dysfunctional psychological functioning in the face of adversity (Abeloff et al. 2004). High levels of psychological distress can lead to serious psychological problems which may need treatment (Weissman et al. 2015). There are individual differences in how much stress one can tolerate because there is a wide array of psychosocial and socioeconomic factors affecting the experience of psychological distress during the pandemic, such as the amount of exposure to negative content in the media, social support, subjective experience of COVID-19, and length of isolation (Arslan 2020a; Zhang et al. 2020). In addition, perceived risk, severity, and self-efficacy related to COVID-19 as well as the state of mental health can also affect the level of psychological distress (Yıldırım and Güler 2020). All these factors could have an impact on one's resilience and mental health condition.

Studies have demonstrated that meaningful living and psychological health are closely associated. Research has shown that meaningful living can predict hope and depressive symptoms uniquely and prospectively (Mascaro and Rosen 2005). Tragic optimism can also assist victims to overcome abuse and post-traumatic stress disorder and promote their wellbeing by helping them to a new level of resilience and vitality (Wong and McDonald 2002). Furthermore, Jans-Beken and Wong (2019) highlighted that having a sense of existential gratitude is beneficial for individuals with a traumatic history. Previous research has also showed that individuals with high 
levels of meaning in their life have higher levels of subjective wellbeing, psychological wellbeing, quality of life, and optimism (Braaten et al. 2019; Minkkinen et al. 2020; Ho et al. 2010); self-efficacy (DeWitz et al. 2009); self-esteem (Schlegel et al. 2011); adaptive coping strategies (Edwards and Holden 2001) and lower levels of psychological distress such as anxiety and depression (Korte et al. 2012); stress (Bauer-Wu and Farran 2005); and suicidal thoughts (Edwards and Holden 2001).

Within the context of the pandemic, studies demonstrated that patients who were diagnosed with COVID-19 experienced higher prevalence of depression (29.2\%) and anxiety (21.1\%). A high level of anxiety (22.4\%) among the general public was also reported (Zhang et al. 2020). Similar results have been reported in another study comparing four groups of participants-patients with COVID-19, medical students, medical workers, and general population-in the degrees of selfreported mental health problems. In that study, although high levels of psychological distress were observed among four groups of people, medical students and patients diagnosed with COVID-19 were at the high risk of developing some mental health problems by reporting higher levels of stress, anxiety and depression compared to their counterparts (Ashtari et al. 2020). This finding is alarming and requires an urgent need for investigating psychological distress during pandemic. Meaningful living can function as a factor in protecting the psychological health of individuals during pandemic.

\section{Meaningful Living, Affective Balance, and Resilience}

Literature suggest that meaningful living is an important capacity that can foster wellbeing (Oliver et al. 2006; Wong $2012 b$ ). Wellbeing is generally measured by subjective wellbeing, defined as comprising affective and cognitive evaluations of one's life (Diener et al. 2018). The affective component refers to evaluation of the emotions that individuals experience in their day-to-day lives, such as feeling good, upset, nervous, afraid, excited, attentive, and proud (Watson et al. 1988). Affective balance is conceptualized as the predominance of positive affect over negative affect (Diener et al. 2018). Affective balance contributes to life satisfaction (Diener and Larsen 1993). Cognitive component (satisfaction with life) refers to a judgment process that people evaluate their life as satisfactory (Diener et al. 1985). Positive emotions facilitate the ability of problem solving by creating many possible solutions to problems, and in turn, this increased coping ability can predict experience of positive emotions in future. With this continuous cycle, individuals can develop their psychological resilience and increase their emotional wellbeing and psychological health (Fredrickson and Joiner 2002). In a study, researchers demonstrated that affective balance exerted a direct effect on life satisfaction and mediated the relationship between resilience and life satisfaction (Liu et al. 2013).

Resilience has been a topic of interest within the burgeoning literature of human strengths. Resilience is a salient psychological strength that can reduce detrimental effect of stressors on psychological health (Arslan 2016). The concept of resilience has been identified as an ability to cope with and adapt effectively in response to major stressors (Luthar 2003; Luthar et al. 2000). Resilience has also been conceptualized as a critical psychological resource that refers to the ability of "bounce back" from stress quickly, adapt to new situation flexibly, and even psychologically change in a positive way in the face of the adversity (Bonanno 2004). Researchers have typically considered resilience as a multidimensional construct (Luthar et al. 2000). However, some researchers considered resilience as a unidimensional construct and measured it accordingly (McKay, Skues, \& Williams, 2019). For example, Smith et al. (2008) argued that it was necessary to measure resilience in its original and most basic meaning of "bouncing back or recovering from stress". The present study adopted the unidimensional measure. Although resilience has been defined in a variety of ways, viewing resilience as the ability of "bounce back" from adversity is of great importance and beneficial in terms of research, both for the progression of scientific knowledge and for its practical application. Understanding resilience as the ability to bounce back from stress can be very important for the assessment of positive and negative indicators of individuals' functioning, especially for developing programs aimed at improving resilience when understood as an ability (Konaszewski et al. 2020; Yıldırım and Çelik-Tanrıverdi 2020).

\section{Affective Balance, Resilience, and Psychological Health}

Research has shown that resilience is related to successful outcomes in human functioning in adversity. For example, studies have highlighted that resilience can function as a protective factor under stressful conditions, by diminishing potential risk associated with adjustment problems and increasing positive psychological outcomes (Florez et al. 2020; Tedeschi and Kilmer 2005). The impact of positive emotions on resilience and psychological health has been studied in previous research, suggesting that positive emotions have a direct effect on resilience and psychological health. Resilience was also found to have a direct effect on psychological health (Gloria and Steinhardt 2016). Furthermore, research shows that affective balance is associated with a wide range of factors including meaningful living (Ho et al. 2010; Steger et al. 2006, 2009b; Yalçın and Malkoc 2015); healthrelated quality of life (Moon et al. 2018); daily emotional experiences (Veilleux et al. 2020), depressive symptoms 
(Pieruccini-Faria et al. 2018); personal wellbeing and social capital (Veronese et al. 2018); and self-esteem (Liang et al. 2020).

With regard to resilience, a growing literature demonstrates that resilience is a significant predictor of psychological distress, subjective wellbeing, and quality of life (Yildirim and Belen 2018; McDonnell and Semkovska 2020; Tecson et al. 2019); affective balance, life satisfaction, and psychosocial wellbeing, and decreased negative affect (Yildirim 2019); moods, depression, and anxiety (Burns et al. 2011). Furthermore, resilience mediates the relationship affective balance and cognitive impairment (Xie et al. 2019). Within the context of COVID-19, a recent study showed that resilience had a significant direct effect on subjective wellbeing and psychological health among the general public during the early phase of COVID-19 (Yildirim and Arslan 2020). Collectively, evidence shows that psychological resilience and positive emotions can buffer the negative impacts of daily life stress on psychological health (Ong et al. 2006). These findings suggest that resilience is associated with positive mental health outcomes.

\section{Present Study}

Given that psychological health and wellbeing are of the utmost importance during the pandemic (Yildirim and Arslan 2020; Y1ldirım et al. 2020), this study aimed to examine the impact of meaningful living, affective balance, and resilience on psychological health. Based on the preceding rationale and extant literature where the importance of meaningful living and psychological strengths (i.e., optimism and resilience) in promoting psychological heath has been established within the context of COVID-19 (Arslan and Yildirim 2020), we hypothesized that (i) meaningful living would have a direct effect on positive affect, negative affect, resilience, and psychological health; (ii) positive affect and negative affect would have direct effect on resilience and psychological health; (iii) resilience would have a direct effect on psychological health; (iv) positive affect and negative affect would mediate the relationship between meaningful life and resilience and psychological health; (v) resilience would mediate the relationship between meaningful life and psychological health; and (vi) resilience would mediate the relationship between positive affect and negative affect and psychological health.

\section{Method}

\section{Participants}

The participants of the current study were 359 Turkish young adults, comprising of primarily females (68.2\%), and their age ranged between 18 to 43 years (age $M=20.67, S D=3.62$ ), see Table 1. With regard to adults' coronavirus experiences, $68.2 \%$ were in quarantine or were imposed to stay-at-home, and two participants were also infected. Other participants reported that they self-isolated themselves. An online survey portal was created using demographic items and the measures of the study. Institutional review board approval was obtained before the data collection process, and the participants were informed that participation in the study was voluntary, the survey was confidential, and they could quit the survey at any time if they did not want to continue. Data collection took place between 15 and 28 April 2020 during the pandemic. Prior to data collection process, an electronic assent form was signed by adults who volunteered to participate in the study.

\section{Measures}

Meaningful Living Meaningful living was measured using the Meaningful Living Measure (MLM; Arslan 2020b) that is a 6item self-report scale (e.g., "As a whole, I find my life meaningful"). All items of the scale are scored using a 7-point Likert type scale ranging from strongly disagree (1) to strongly agree (7). Previous research has revealed that the MLM had strong internal reliability estimates with Turkish sample (Arslan 2020b). Findings of this study indicated that the scale provided a strong internal reliability estimate with the present sample, see Table 1.

Psychological Health Problems The Brief Symptom Inventory (BSI-18) was used to measure adults' psychological health problems (Derogatis and Fitzpatrick 2004). The scale is an 18-item self-report survey, comprising of six-item subscales: depression, anxiety, and somatization (e.g., "Feeling no interest in things", "Pains in heart or chest"). All items of the scale are responded using a 5-point Likert type scale, ranging from not at all (0) to very much (4). Previous research indicated that the scale and its subscales had strong internal reliability estimates for Turkish university adults (Arslan et al. 2020). In the present study, total scores of the scale were used, and the scale also had a strong internal reliability estimate with this sample, see Table 1.

Resilience The Brief Resilience Scale (BRS) was used to measure resilience as bouncing back from negative life experiences (Smith et al. 2008). The BRS is a 6-item self-report measure (e.g., "I tend to bounce back quickly after hard times), scoring all items of it using a 5-point Likert scale ranging between strongly disagree (1) and strongly agree (5). Previous research provided evidence supporting that the scale had strong internal reliability estimate with Turkish sample (Doğan 2015). The scale also had a strong internal reliability estimate with the present sample, see Table 1. 
Table 1 Demographic characteristics of participants

\begin{tabular}{ll}
\hline Demographic variable & \\
\hline Gender & \\
$\quad$ Female & $68.2 \%$ \\
Male & $31.8 \%$ \\
Age & \\
Range & $18-43$ \\
Mean $(S D)$ & $20.67(3.62)$ \\
Socioeconomic status (SES) & \\
$\quad$ Low SES & $8.4 \%$ \\
Moderate SES & $76.3 \%$ \\
$\quad$ Upper SES & $15.3 \%$ \\
Health status & \\
Healthy & $99.4 \%$ \\
Were infected with the COVID-19 & $.6 \%$ \\
COVID-19 limitations & $68.2 \%$ \\
Quarantine or were imposed to stay-at-home & $31.8 \%$ \\
Self-isolation with the ability to move and social contacts
\end{tabular}

Affective Balance The Scale of Positive and Negative Experience (SPANE; Diener et al. 2010) were combined to measure individuals' subjective wellbeing. The SPANE is a 12-item self-report questionnaire used to assess individuals' emotions and moods and includes two six-item subscales: Positive Feelings Scale (PAS; e.g., "Pleasant", "Good") and Negative Affect Scale (NAS; e.g., "Unpleasant", "Negative"). All items of the scale are rated on a 5-point Likert scale, ranging from very rarely or never (1) to 'very often or always (5). Research indicated that the scale had good psychometric properties and strong internal reliability estimates for Turkish samples (Telef 2013). Internal reliability estimates of the scale were adequate-strong with the present sample, Table 1.

\section{Data Analyses}

Preliminary analyses were first conducted to examine descriptive statistics (e.g., mean, standard deviation), the normality assumption and internal reliability estimates of the variables. Subsequently, Pearson product-moment correlation analysis was performed to investigate the associations between meaningful living, positive and negative affect, resilience, and psychological health. Normality assumption was investigated using kurtosis and skewness scores and their cut-off values and their scores lower than $|2|$ is an acceptable range for being normally distributed (D'Agostino et al. 1990; Field 2009). Second, we conducted a mediation model to analyse the mediating role of affective balance and resilience in association between meaningful living and psychological health using the PROCESS macro (Model 80) for SPSS version 3.4 (Hayes 2018). Findings from this analysis were interpreted using standardized regression estimate $(\beta)$ scores and squaredmultiple correlations $\left(R^{2}\right)$, with traditional effect sizes: $.01-.059=$ small, $.06-.139=$ moderate, and $\geq .14=$ large (Cohen 1988). Moreover, the bootstrapping method with 10,000 resamples to estimate the $95 \%$ confidence intervals (CI) was conducted to examine the significance of indirect effects (Hayes 2018; Preacher and Hayes 2008). The bootstrapping approach is specified to be a significantly more effective method than other methods, especially for research with a relatively smaller sample size (Hayes 2009; Preacher and Hayes 2008). Therefore, we examined bias-corrected bootstrapping procedures to test the mediation model. All analyses were conducted using SPSS version 25 .

\section{Results}

\section{Preliminary Analysis}

Findings from preliminary analysis indicated that kurtosis values were between -1.14 and .73 , and skewness scores ranged from -1.44 and .13 , and these scores suggested that all variables had relatively normal distribution (skewness and kurtosis values $<|2|)$. The internal reliability estimates of the scales were investigating showing that the scales had adequate-to-strong internal reliability coefficients (range $\alpha=.77$ to .92), as shown in Table 1. We investigated the univariate and multivariate outliers using $z$-scores $(z \pm 4)$ and Mahalanobis distance, and three outliers was excluded from the analyses (Stevens 2009; Tabachnick and Fidell 2013).

With regard to demographic characteristics, a significant difference was found on the scores of resilience $(t=-3.50$, $p<.001)$ and negative affect $(t=5.28, p<.001)$ based on the gender of participants, indicating that males reported greater resilience $(M=19.53, S D=5.06)$ and less negative emotions $(M=14.72, S D=3.54)$ than females $(M=17.47-16.81, S D=$ 5.46-3.39). A non-significant difference was also found on the scores of meaningful living $(t=-1.08, p=.28)$, resilience $(t=-.85, p=.39)$, positive affect $(t=1.13, p=.35)$, and negative affect $(t=1.85, p=.06)$ based on COVID-19 limitations (i.e., quarantine or were imposed to stay-at-home versus selfisolation with the ability to move and social contacts). However, a significant difference was found regarding psychological health problems $(t=2.31, p<.05)$ based on COVID-19 limitations, and the participants who were in quarantine or were imposed to stay-at-home reported greater psychological health problems than those who were self-isolation with the ability to move and social contacts $(M=21.84-18.25$, $S D=13.19-12.93)$. Especially, the participants who were in quarantine or imposed to stay-at-home significantly had higher levels of anxiety $(t=2.83, p<.05 ; M=4.77-4.29)$ and somatization $(t=2.73, p<.05 ; M=5.92-4.42)$ than those who were not. 
Subsequently, findings from correlation analysis showed that meaningful living was positively and moderately associated with positive feelings $(r=.41, p<.001)$ and resilience $(r=.29, p<.001)$, as well as had negative and smallmoderate correlations with negative affect $(r=-.22$, $p<.001)$ and psychological health problems $(r=-.42$, $p<.001)$. Positive affect was positively and moderately related to resilience $(r=.37, p<.001)$ and negatively and moderately correlated with psychological health problems $(r=-.35$, $p<.001)$. There was a positive and moderate correlation between negative feelings and psychological health problems $(r=.43, p<.001)$, and negative feelings was also negatively and moderately correlated with resilience $(r=-.38, p<.001)$, as shown in Table 2.

\section{Mediation Analyses}

After examining the preliminary analyses, the mediation model was conducted to examine the direct and indirect relationships between variables. Findings from the mediation analysis firstly revealed that meaningful living significantly predicted positive $(\beta=.41, p<.001)$ and negative affect $(\beta=-.21, p<.001)$, accounting for $17 \%$ of the variance in positive feelings and for $5 \%$ of the variance in negative affect. Meaningful living also had a direct and significant predictive effect on resilience $(\beta=.15, p<.05)$ and predicted resilience through positive $(\beta=.23$, $p<.001)$ and negative feelings $(\beta=-.25, p<.001)$ significantly. Meaningful living and affective balance components together accounted for $21 \%$ of the variance in resilience, as shown in see Table 3 and Fig. 1. These results suggest that affective balance, namely positive and negative feelings, has a mediation effect in the association of meaningful living with resilience.

Next, the results showed that meaningful living had significant predictive effect on psychological health problems $(\beta=$ $-.28, p<.001)$. Psychological health was also significantly predicted by negative affect $(\beta=.27, p<.001)$ and resilience ( $\beta=-.17, p<.001)$, but positive feelings did not directly predict psychological health $(\beta=-.08, p=.13)$. All the variables together accounted for $32 \%$ of the variance in psychological health problems. These results provide evidence indicating that meaningful living predicted psychological health through resilience and affective balance. Resilience also partially mediates the association of negative feelings with psychological health while has a full mediation effect in the relationship between positive affect and psychological health, as shown in Table 3 and Fig. 1. The indirect effects of meaningful living on psychological health through mediators was significant. Unstandardized total, direct and indirect effects, and 95\% bias-corrected confidence interval predicting psychological health scores are presented in Table 4.

\section{Discussion}

The present study sought to investigate the mediating effect of the affective balance and resilience on the association between meaningful living and psychological health problems among Turkish young adults in the context of the COVID-19 pandemic. Prior to testing the mediation model, preliminary results revealed that there was a non-significant difference on the scores of meaningful living, resilience, positive affect, and negative affect based on COVID-19 limitations (i.e., quarantine or were imposed to stay-at-home versus self-isolation with the ability to move and social contacts). However, a significant difference was found regarding psychological health problems based on COVID-19 limitations, and individuals who were in quarantine or were imposed to stay-at-home reported greater psychological health problems than those who were self-isolation with the ability to move and social contacts. Specifically, individuals who were in quarantine or imposed to stay-at-home significantly reported higher levels of anxiety and somatization than those who were not. During the outbreak, prevalence of mental health challenges has increased substantially, especially among those with preexisting psychological conditions, and further worsening their daily functioning and cognition (Yang et al. 2020). Similar to these results, Ettman et al. (2020) found that people had greater depressive symptoms (more than 3-fold) during coronavirus pandemic compared with before the pandemic. Huang et al. (2020) also found that approximately $33 \%$ of people experienced anxiety, and $8 \%$ of people reported somatization during the COVID-19 outbreak. These results suggest that coronavirus experiences can cause serious psychosocial health consequences, and people who have coronavirus experiences ((e.g., quarantine or were imposed to stay-at-home) are more likely to have psychological health challenges than those without.

Findings from this study revealed that meaningful living had a significant predictive effect on affective balance components, including positive and negative affect. Specifically, meaningful living more strongly predicted positive affectivity compared with negative affectivity and was also a significant and negative predictor of psychological health problems of adults. The results of this study are consistent with previous evidence indicating the association between meaningful living and affective balance (Ho et al. 2010; Steger et al. 2006; Steger et al. 2009b; Yalçın and Malkoç 2015) and psychological health indicators, such as depression, anxiety, somatization, and alienation (Bauer-Wu and Farran 2005; Brassai et al. 2011; Du et al. 2017; Ho et al. 2010; Korte et al. 2012; Steger et al. 2006, 2009a). For example, Steger et al. (2009b) reported that meaning in life was associated with a variety of wellbeing and psychological health indicators (e.g., life satisfaction, positive affect, happiness, and depression) at all life stages. Given the PP 2.0 framework, meaning is a key to 
Table 2 Descriptive statistics and correlation results $(N=359)$

\begin{tabular}{|c|c|c|c|c|c|c|c|c|c|c|}
\hline Scales & $M$ & $S D$ & Skew. & Kurt. & $\alpha$ & 1. & 2. & 3. & 4. & 5. \\
\hline 1. Meaningful living & 33.95 & 5.62 & -1.14 & -1.44 & .80 & - & $.41^{* *}$ & $-.22^{* *}$ & $.29^{* *}$ & $-.42^{* *}$ \\
\hline 2. Positive affect & 20.14 & 4.33 & -.34 & .13 & .90 & & - & -.33 & .37 & -.35 \\
\hline 3. Negative affect & 16.15 & 3.57 & -.09 & -.06 & .77 & & & - & -.35 & .43 \\
\hline 4. Resilience & 18.13 & 5.42 & .01 & -.17 & .86 & & & & - & -.38 \\
\hline 5. Psychological health & 20.75 & 13.19 & .73 & .01 & .92 & & & & & - \\
\hline
\end{tabular}

*** Correlation is significant at the .001 level (2-tailed)

psychological health and flourishing of individuals (Frankl 1985; Wong 2016b), and meaningful living help individuals to overcome psychological challenges and foster their wellbeing by helping them to move beyond not only to survive but also a new level of resilience and vitality (Wong and McDonald 2002). Reker and Wong (1988) emphasized that "the realization of personal meaning is always accompanied by feelings of satisfaction and fulfilment" (p. 221). Therefore, meaningful experiences may lead to more positive affective experiences and promote psychological health and wellbeing. Within this theoretical and empirical context, the sense of meaning in life might facilitate the experience of positive affectivity and contribute to promoting the psychological health of individuals. Hereby, these results suggest that individuals with high levels of meaningful living have higher levels of positive affect, as well as lower levels of negative affect and psychological health challenges.

Results from the current study further showed that positive and negative affect significantly predicted resilience and mediated the effect of meaningful living on this construct. These results indicate the importance of affective balance in building and promoting resilience among young adults. Affective balance is a construct referring to the balance between negative and positive affect (Diener et al. 2018), and the frequency and intensity of the positive and negative feelings of individual (Reis and Hoppe 2015). According to broaden-and-build theory (Fredrickson 2001, 2005), positive emotions widen human cognition and stimulate people to think more freely, creatively, and thoughtfully, which in turn help them to find a positive meaning within adversity and view the world with a wider perspective. As a consequence of this, individuals who experience high levels of positive emotions have an ability to produce various possible coping strategies in the face of adversity (Fredrickson and Joiner 2002). Consistent with the outcomes of this study, previous research indicated that affective balance was associated with a variety of quality of life and psychological health outcomes, including depression symptoms, resilience, and self-esteem (Arslan 2015a; Karairmak and Siviş-Çetinkaya 2011; Kelle and Uysal Irak 2018; Liang et al. 2020; Pieruccini-Faria et al. 2018; Veronese et al. 2018). For example, Arslan (2015b) found a large predictive effect of positive affectivity on resilience, and positive affect was reported as an important source in the building of resilience in adolescence to adulthood (Arslan 2016; Tugade and Fredrickson 2004). Positive feelings may contribute

Table 3 Unstandardized coefficients for the mediation model

\begin{tabular}{|c|c|c|c|c|c|c|c|c|c|c|c|c|c|c|c|c|}
\hline \multirow[b]{3}{*}{ Antecedent } & \multicolumn{16}{|c|}{ Consequent } \\
\hline & \multicolumn{4}{|c|}{$M_{l}$ (Positive Affect) } & \multicolumn{4}{|c|}{$M_{2}$ (Negative Affect) } & \multicolumn{4}{|c|}{$M_{3}$ (Resilience) } & \multicolumn{4}{|c|}{$Y$ (Psychological health) } \\
\hline & Coeff. & $S E$ & $t$ & $p$ & Coeff. & $S E$ & $t$ & $p$ & Coeff. & $S E$ & $t$ & $p$ & Coeff. & $S E$ & $t$ & $p$ \\
\hline$X$ (Meaning) & .31 & .03 & 8.47 & $<.001$ & -.14 & .03 & -4.13 & $<.001$ & .14 & .05 & 2.86 & .004 & -.64 & .11 & -5.74 & $<.001$ \\
\hline$M_{l}$ (Positive) & - & - & - & - & - & - & - & - & .28 & .07 & 4.18 & $<.001$ & -.23 & .15 & -1.49 & .135 \\
\hline$M_{2}$ (Negative) & - & - & - & - & - & - & - & - & -.37 & .08 & -4.88 & $<.001$ & .96 & .17 & 5.53 & $<.001$ \\
\hline$M_{3}$ (Resilience) & - & - & - & - & - & - & - & - & - & - & - & - & -.40 & .12 & -3.41 & $<.001$ \\
\hline \multirow[t]{2}{*}{ Constant } & 9.51 & 1.27 & 7.47 & $<.001$ & 20.71 & 1.11 & 18.50 & $<.001$ & 13.64 & 2.43 & 5.60 & $<.001$ & 38.64 & 5.57 & 6.92 & $<.001$ \\
\hline & \multicolumn{4}{|c|}{$\begin{array}{l}R^{2}=.17 \\
F=67.61 ; p<.001\end{array}$} & \multicolumn{4}{|c|}{$\begin{array}{l}R^{2}=.05 \\
F=17.02 ; p<.001\end{array}$} & \multicolumn{4}{|c|}{$\begin{array}{l}R^{2}=.21 \\
F=29.30 ; p<.001\end{array}$} & \multicolumn{4}{|c|}{$\begin{array}{l}R^{2}=.32 \\
F=40.98 ; p<.001\end{array}$} \\
\hline
\end{tabular}

$S E=$ standard error. Coeff $=$ unstandardized coefficient. $X=$ independent variable; $M=$ mediator variables; $Y=$ outcomes or dependent variables 
Fig. 1 Structural model demonstrating the association between the variables of study

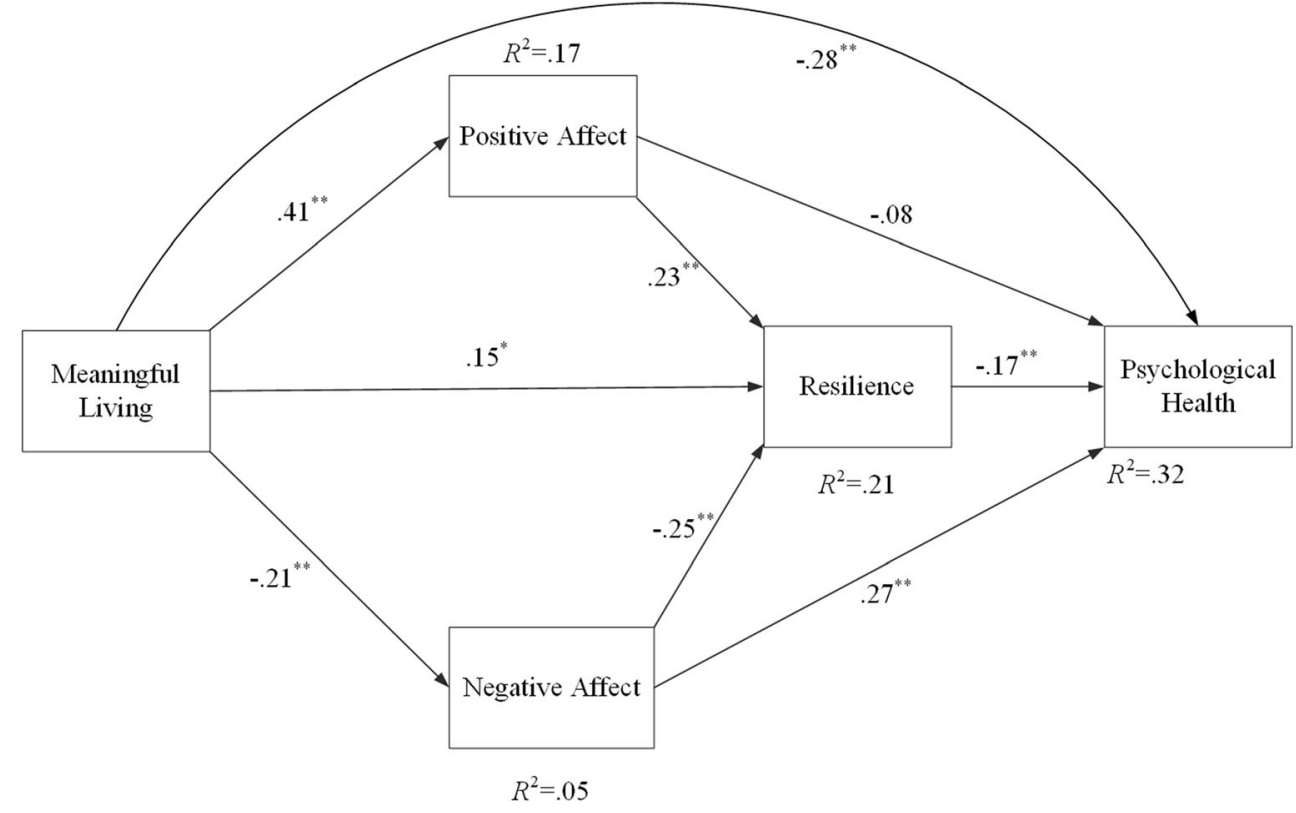

to people's cognitions and behaviours to build their psychological and social resources. Thereby, resilient individuals are more likely to report positive emotions even when experience adversity (Strand et al. 2006; Tugade and Fredrickson 2004).

As importantly, findings of the study revealed that resilience fully mediated the association between positive affect and psychological health, while partially mitigated the effect of negative affect on psychological health of adults. Moreover, resilience partially mediated the effect of meaningful living on psychological health. Resilience is an important psychological strength to improve wellbeing and address the psychological health (Arslan 2019; Bonanno 2004; Luthar 2003; Luthar et al. 2000). Findings from this study are consistent with literature supporting the association between affective balance, resilience, and psychological health (Arslan 2015a; Du et al. 2017; Karaırmak and Siviş-Çetinkaya 2011; Kim et al. 2005; Tugade and Fredrickson 2004; Wong and
Wong 2012). Meaning was both empirically and theoretically emphasized as an important resource for resilience (Wong and Wong 2012), and the sense of meaningful life help people to bounce back in the face of challenges by providing personal resources and adaptive flexibility. Frankl (1985) highlighted that all individuals have the will to meaning, which in turn contributes to overcoming challenges in order to live meaningfully. Additionally, findings of the study revealed that resilience mediated the effect of meaningful living and affective balance on psychological health among young adults. Consistent with these results, previous research indicated the mediating effect of resilience on psychological health problems in the context of various adverse experiences (e.g., child maltreatment, social exclusion, and stress; Arslan 2016, 2019; Karaırmak and Siviş-Çetinkaya 2011; Lee et al. 2018; Shi et al. 2015). A meta-analysis study by $\mathrm{Hu}$ et al. (2015) revealed that individuals with lower resilience reported greater depression, negative affect, and anxiety, as well as lower

Table 4 Unstandardized total, direct and indirect effects, and 95\% bias-corrected confidence interval predicting psychological health scores

\begin{tabular}{|c|c|c|c|c|}
\hline Path & Effect & $S E$ & BootLLCI & BootULCI \\
\hline Total effect & -.95 & .11 & -1.16 & -.74 \\
\hline Direct effect & -.63 & .10 & -.85 & -.41 \\
\hline Total indirect effect & -.31 & .07 & -.46 & -.18 \\
\hline Meaning->Positive- $>$ Psychological health & -.07 & .05 & -.18 & .03 \\
\hline Meaning $->$ Negative $->$ Psychological health & -.12 & .05 & -.23 & -.07 \\
\hline Meaning $->$ Resilience- $>$ Psychological health & -.05 & .03 & -.13 & -01 \\
\hline Meaning $->$ Positive $->$ Resilience $->$ Psychological health & -.04 & .02 & -.07 & -.01 \\
\hline Meaning $->$ Negative $->$ Resilience $->$ Psychological health & -.02 & .01 & -.04 & -.01 \\
\hline
\end{tabular}

Number of bootstrap samples for percentile bootstrap confidence intervals: 10000 
positive affect and life satisfaction than those with higher resilience. Similar to the findings of this study, Loh et al. (2014) reported that resilience partially mitigated the effect of negative emotions on depressive symptoms while fully mediated the association between positive affect and depressive symptoms. Within the context of COVID-19, a recent study showed that resilience had a significant direct effect on subjective wellbeing and psychological health among the general public during early phase of COVID-19 (Yildirim and Arslan 2020). Individuals with high resilience are able to use more flexible strategies and to have an ability to self-regulate themselves in the face of adverse events (Loh et al. 2014; Tugade and Fredrickson 2004). Therefore, they are more likely to report fewer psychological health challenges compared with those with lower resilience.

\section{Conclusion and Limitations}

Findings from this study indicated that meaningful living has a positive predictive effect on resilience and positive affect, as well as a negative predicative on psychological health challenges and negative affect. Resilience and affective balance also mediate the effect of meaningful living on psychological health of young adults. These results suggest that resilience and affective balance are important aspects of implementing meaning-based preventions and interventions. Thus, meaning-based prevention and intervention strategies could be designed to not only to improve individuals' life meaning and purpose but also build up resilience and positive affective experiences to foster their psychological health. Additionally, given the importance of meaning in the coping process of adverse experiences (e.g., coronavirus pandemic), mental health providers could use meaning-based strategies to foster the promotion of mental health and reduce the risk of psychological challenges. Furthermore, this study supports that positive affect is key to promote the resilience and psychological health of adults. Thus, positive emotions may be integrated with the meaning approach to improve wellbeing and psychological health. This approach could facilitate individuals to deal with stressors such as the coronavirus pandemic by promoting their resilience resources. Focusing aspects of meaning-preventions and interventions on harnessing positive emotions to improve resilience may cause even greater reductions in psychological health problems.

Although the present study has provided important implication for research and practice, the study was designed using the cross-sectional approach which cannot ascertain a causal relationship among the study variables. Therefore, further studies using longitudinal designs are warranted to offer additional insights into the associations between the variables of the study. Subsequently, self-reported measures are considered another limitation of this study, and future research should use multiple techniques (e.g., qualitative and quantitative) for the investigation of the relationship between the study variables. Given the characteristics of the sample in the present study, future research could be conducted using different samples to investigate the associations that were found in this study. Furthermore, future studies are needed to tested positive affective balance and resilience from the perspective of PP 2.0, where people are trained to adopt the attitude of embracing suffering. Lastly, given that resilience is a multidimensional construct in nature (Luthar et al. 2000), applying a multidimensional strategy toward operationalizing resilience in future study would be useful to examine the relationships between the measured variables used in this study.

Data Availability The datasets generated during and/or analysed during the current study are available from the corresponding author on reasonable request.

\section{Compliance with Ethical Standards}

Conflict of Interest The authors declared no conflicts of interest with respect to the research, authorship, and/or publication of this article.

Ethical Approval All procedures performed in studies involving human participants were in accordance with the ethical standards of the institutional and/or national research committee and with the 1964 Helsinki declaration and its later amendments or comparable ethical standards.

Informed Consent Informed Consent was obtained from all participants included in the study.

\section{References}

Abeloff, M. D., Armitage, J. O., Niederhuber, J. E., Kastan, M. B., \& McKenna, W. G. (2004). Review of clinical oncology. Philadelphia: Churchill Livingstone.

Arslan, G. (2015a). Ergenlerde psikolojik sağlamlık: Bireysel koruyucu faktörlerin rolü. Türk Psikolojik Danışma ve Rehberlik Dergisi, 5(44), 73-82.

Arslan, G. (2015b). Çocuk ve Genç Psikolojik Sağlamlık Ölçeği'nin (ÇGPSÖ) psikometrik özellikleri: Geçerlilik ve güvenirlik çalıșması. Ege Eğitim Dergisi, 16(1), 1-12.

Arslan, G. (2016). Psychological maltreatment, emotional and behavioral problems in adolescents: The mediating role of resilience and selfesteem. Child Abuse and Neglect, 52, 200-209. https://doi.org/10. 1016/j.chiabu.2015.09.010.

Arslan, G. (2019). Mediating role of the self-esteem and resilience in the association between social exclusion and life satisfaction among adolescents. Personality and Individual Differences, 151, 109514. https://doi.org/10.1016/j.paid.2019.109514.

Arslan, G. (2020a). Loneliness, college belongingness, subjective vitality, and psychological adjustment during coronavirus pandemic: Development of the College Belongingness Questionnaire. Journal of Positive School Psychology. Retrieved from https:// journalppw.com/index.php/JPPW/article/view/240.

Arslan, G. (2020b). Anlamlı Yaşam Ölçeğinin geliştirilmesi: Anlamlı yașama ilișkin kısa ve etkili bir ölçme aracı [Development of the Meaningful Living Measure: A brief and effective measure of meaningful living]. Mehmet Akif Ersoy University Journal of Education Faculty, 56, 227-242. https://doi.org/10.21764/maeuefd.773686. 
Arslan, G., \& Yildirim, M. (2020). Coronavirus stress, meaningful living, optimism, and depressive symptoms: A study of moderated mediation model, PsyArXiv, preprint doi: https://oi.org/10.31234/osf.io/ ykvzn.

Arslan, G., Yıldırım, M., Karataș, Z., Kabasakal, Z., \& Kılınç, M. (2020). Meaningful living to promote complete mental health among university students in the context of the COVID-19 pandemic. International Journal of Mental Health and Addiction. https://doi. org/10.1007/s11469-020-00416-8.

Ashtari, S., Vahedian-Azimi, A., Moayed, M. S., Rahimibashar, F., Shojaei, S., \& Pourhoseingholi, M. A. (2020). Compare the severity of psychological distress among four groups of Iranian society in COVID-19 pandemic. https://doi.org/10.21203/rs.3.rs-23828/v1.

Batthyany, A., \& Russo-Netzer, P. (Eds.). (2014). Meaning in positive and existential psychology. New York, NY: Springer.

Bauer-Wu, S., \& Farran, C. J. (2005). Meaning in life and psychospiritual functioning: A comparison of breast cancer survivor and healthy women. Journal of Holistic Nursing, 23(2), 172-190.

Bonanno, G. A. (2004). Loss, trauma, and human resilience. American Psychologist, 59, 20-28.

Braaten, A., Huta, V., Tyrany, L., \& Thompson, A. (2019). Hedonic and eudaimonic motives toward university studies: How they relate to each other and to well-being derived from school. Journal of Positive School Psychology, 3(2), 179-196.

Brassai, L., Piko, B. F., \& Steger, M. F. (2011). Meaning in life: Is it a protective factor for adolescents' psychological health? International Journal of Behavioral Medicine, 18(1), 44-51. https://doi.org/10.1007/s12529-010-9089-6.

Burns, R. A., Anstey, K. J., \& Windsor, T. D. (2011). Subjective wellbeing mediates the effects of resilience and mastery on depression and anxiety in a large community sample of young and middleaged adults. Australian and New Zealand Journal of Psychiatry, 45(3), 240-248.

Center for Systems Science and Engineering. (2020). Coronavirus COVID-19 global cases at Johns Hopkins University. https:// coronavirus.jhu.edu/map.html

Cohen, J. (1988). Statistical power analysis for the behavioural sciences (2nd ed.). Hillsdale, NJ: Lawrence Erlbaum.

D'Agostino, R. B., Belanger, A., \& D'Agostino, R. B. (1990). A suggestion for using powerful and informative tests of normality. The American Statistician, 44(4), 316. https://doi.org/10.2307/2684359.

de Cates, A., Stranges, S., Blake, A., \& Weich, S. (2015). Mental wellbeing: An important outcome for mental health services? The British Journal of Psychiatry, 207(3), 195-197.

Derogatis, L. R., \& Fitzpatrick, M. (2004). The SCL-90-R, the Brief Symptom Inventory (BSI), and the BSI-18. In M. E. Maruish (Ed.), The use of psychological testing for treatment planning and outcomes assessment: Instruments for adults, volume 3 (3rd ed., pp. 1-41). Mahwah, NJ, US: Lawrence Erlbaum Associates Publishers.

DeWitz, S. J., Woolsey, M. L., \& Walsh, W. B. (2009). College student retention: An exploration of the relationship between self-efficacy beliefs and purpose in life among college students. Journal of College Student Development, 50(1), 19-34.

Diener, E., \& Larsen, R. J. (1993). The experience of emotional wellbeing. In M. Lewis \& J. M. Haviland (Eds.), Handbook of emotions (pp. 405-415). New York: Guilford.

Diener, E. D., Emmons, R. A., Larsen, R. J., \& Griffin, S. (1985). The satisfaction with life scale. Journal of Personality Assessment, 49(1), 71-75.

Diener, E., Wirtz, D., Tov, W., Kim-Prieto, C., Choi, D., Oishi, S., \& Biswas-Diener, R. (2010). New wellbeing measures: Short scales to assess flourishing and positive and negative feelings. Social Indicators Research, 97(2), 143-156. https://doi.org/10.1007/ s11205-009-9493-y.
Diener, E., Lucas, R. E., \& Oishi, S. (2018). Advances and open questions in the science of subjective wellbeing. Collabra Psychology, 4(1), 15. https://doi.org/10.1525/collabra.115.

Doğan, T. (2015). Kisa Psikolojik Sağlamlık Ölçeği'nin Türkçe uyarlaması: Geçerlik ve güvenirlik calıșması. The Journal of Happiness \& Wellbeing, 3(1), 93-102.

Du, H., Li, X., Chi, P., Zhao, J., \& Zhao, G. (2017). Meaning in life, resilience, and psychological wellbeing among children affected by parental HIV. AIDS Care, 29(11), 1410-1416. https://doi.org/10. 1080/09540121.2017.1307923.

Edwards, M. J., \& Holden, R. R. (2001). Coping, meaning in life and suicidal manifestations examining gender differences. Journal of Clinical Psychology, 57(12), 1517-1534.

Ettman, C. K., Abdalla, S. M., Cohen, G. H., Sampson, L., Vivier, P. M., \& Galea, S. (2020). Prevalence of depression symptoms in US adults before and during the COVID-19 pandemic. JAMA network open, 3(9), e2019686-e2019686. https://doi.org/10.1001/ jamanetworkopen.2020.19686.

Field, A. (2009). Discovering statistics using SPSS. London: Sage publications.

Florez, E., Cohen, K., Ferenczi, N., Linnell, K., Lloyd, J., Goddard , L., Kumashiro, M., \& Freeman, J. (2020). Linking Recent Discrimination-Related Experiences and Wellbeing via Social Cohesion and Resilience. Journal of Positive School Psychology, 4(1-Sup1), 92-104.

Frankl, V. E. (1985). Man's search for meaning. Simon and Schuster.

Fredrickson, B. L. (2001). The role of positive emotions of positive psychology: The broaden-and-build theory of positive emotions. American Psychologist, 56, 218-226.

Fredrickson, B. L. (2005). The broaden-and-build theory of positive emotions. In F. A. Huppert, N. Baylis, \& B. Keverne, The science of wellbeing (p. 217-238). Oxford University Press. https://doi.org/ 10.1093/acprof:oso/9780198567523.003.0008.

Fredrickson, B. L., \& Joiner, T. (2002). Positive emotions trigger upward spirals toward emotional wellbeing. Psychological Science, 13(2), 172-175.

Gloria, C. T., \& Steinhardt, M. A. (2016). Relationships among positive emotions, coping, resilience and mental health. Stress and Health, $32(2), 145-156$.

Hayes, A. F. (2009). Beyond baron and Kenny: Statistical mediation analysis in the new millennium. Communication Monographs, $76(4), 408-420$.

Hayes, A. F. (2018). Introduction to mediation, moderation, and conditional process analysis: A regression-based approach. New York: Guilford Press.

Hicks, J. A., \& Routledge, C. (Eds.). (2013). The experience of meaning in life: Classical perspectives, emerging themes, and controversies. New York, NY: Springer.

Ho, M. Y., Cheung, F. M., \& Cheung, S. F. (2010). The role of meaning in life and optimism in promoting wellbeing. Personality and Individual Differences, 48(1), 658-663.

Huang, Y., Wang, Y., Zeng, L., Yang, J., Song, X., Rao, W., et al. (2020). Prevalence and Correlation of Anxiety, Insomnia and Somatic Symptoms in a Chinese Population During the COVID-19 Epidemic. Frontiers in psychiatry, 11, 1-9. https://doi.org/10. 3389/fpsyt.2020.568329.

Hu, T., Zhang, D., \& Wang, J. (2015). A meta-analysis of the trait resilience and mental health. Personality and Individual Differences, 76, 18-27. https://doi.org/10.1016/j.paid.2014.11.039.

Jans-Beken, L., \& Wong, P. T. (2019). Development and preliminary validation of the existential gratitude scale (EGS). Counselling Psychology Quarterly, 1-15.

Karaırmak, Ö., \& Siviș-Çetinkaya, R. (2011). Benlik saygısının ve denetim odağının psikolojik sağlamlık üzerine etkisi: duyguların arac1 rolü. Türk Psikolojik Danısma ve Rehberlik Dergisi, 4(35), 30-43. https://doi.org/10.17066/pdrd.81376. 
Kelle \& Uysal Irak. (2018). Resilience as a mediator between affect, coping styles, support and life satisfaction. Life Skills Journal of Psychology, 2(3), 73-86. https://www.researchgate.net/profile/ Doruk_Uysal_Irak/publication/325583657_Duygulanim Basacikma_Stilleri_Destek_ve_Yasam Doyumu Iliskisinde Psikolojik_Saglamligin_Araci_Rolu/links/ 5b1e30c0aca272021cf597c4/Duygulanim-Basacikma-StilleriDestek-ve-Yasam-Doyumu-Iliskisinde-Psikolojik-SaglamliginAraci-Rolue.pdf

Kim, T.-H., Lee, S. M., Yu, K., Lee, S., \& Puig, A. (2005). Hope and the meaning of life as influences on Korean adolescents' resilience: Implications for counselors. Asia Pacific Education Review, 6(2), 143-152. https://doi.org/10.1007/BF03026782.

Kobau, R., Seligman, M. E., Peterson, C., Diener, E., Zack, M. M., Chapman, D., \& Thompson, W. (2011). Mental health promotion in public health: Perspectives and strategies from positive psychology. American Journal of Public Health, 101(8), e1-e9.

Konaszewski, K., Niesiobędzka, M., \& Surzykiewicz, J. (2020). Validation of the Polish version of the Brief Resilience Scale (BRS). PloS one, 15(8), e0237038.

Korte, J., Cappeliez, P., Bohlmeijer, E. T., \& Westerhof, G. J. (2012). Meaning in life and mastery mediate the relationship of negative reminiscence with psychological distress among older adults with mild to moderate depressive symptoms. European Journal of Ageing, 9(4), 343-351.

Lee, S. W., Bae, G. Y., Rim, H. D., Lee, S. J., Chang, S. M., Kim, B. S., \& Won, S. (2018). Mediating effect of resilience on the association between emotional neglect and depressive symptoms. Psychiatry Investigation., 15, 62-69. https://doi.org/10.4306/pi.2018.15.1.62.

Liang, D., Xu, D., Xia, L., \& Ma, X. (2020). Life satisfaction in Chinese rural-to-urban migrants: Investigating the roles of self-esteem and affective balance. Journal of Community Psychology. https://doi. org/10.1002/jcop.22360.

Liu, Y., Wang, Z., \& Lü, W. (2013). Resilience and affect balance as mediators between trait emotional intelligence and life satisfaction. Personality and Individual Differences, 54(7), 850-855.

Loh, J. M. I., Schutte, N. S., \& Thorsteinsson, E. B. (2014). Be happy: The role of resilience between characteristic affect and symptoms of depression. Journal of Happiness Studies., 15, 1125-1138. https:// doi.org/10.1007/s10902-013-9467-2.

Luthar, S. S. (Ed.). (2003). Resilience and vulnerability: Adaptation in the context of childhood adversities. New York: Cambridge University Press.

Luthar, S. S., Cicchetti, D., \& Becker, B. (2000). The construct of resilience: A critical evaluation and guidelines.

Martela, F., \& Steger, M. F. (2016). The three meanings of meaning in life: Distinguishing coherence, purpose, and significance. The Journal of Positive Psychology, 11(5), 531-545. https://doi.org/10. 1080/17439760.2015.1137623.

Mascaro, N., \& Rosen, D. H. (2005). Existential meaning's role in the enhancement of hope and prevention of depressive symptoms. Journal of Personality, 73(4), 985-1013. https://doi.org/10.1111/j. 1467-6494.2005.00336.x.

McDonnell, S., \& Semkovska, M. (2020). Resilience as Mediator between Extraversion, Neuroticism, and Depressive Symptoms in University Students. Journal of Positive School Psychology, 4(1), 26-40.

McKay, S., Skues, J. L., \& Williams, B. J. (2019). Does the Brief Resilience Scale actually measure resilience and succumbing? Comparing artefactual and substantive models. Advances in Mental Health. Advance online publication. https://doi.org/10. 1080/18387357.2019.1688667.

Minkkinen, J., Auvinen, E., \& Mauno, S. (2020). Meaningful Work Protects Teachers' Self-Rated Health under Stressors. Journal of Positive School Psychology, 4(2), 140-152. https://doi.org/10. 47602/jpsp.v4i2.209.
Moon, H. I., Yoon, S. Y., Jeong, Y. J., \& Cho, T. H. (2018). Sleep disturbances negatively affect balance and gait function in poststroke patients. NeuroRehabilitation, 43(2), 211-218.

Oliver, K. G., Collin, P., Burns, J., \& Nicholas, J. (2006). Building resilience in young people through meaningful participation. Australian e-Journal for the advancement of Mental Health, 5(1), 34-40.

Ong, A. D., Bergeman, C. S., Bisconti, T. L., \& Wallace, K. A. (2006), Psychological resilience, positive emotions, and successful adaptation to stress in later life. Journal of Personality and Social Psychology, 91(4), 730-749.

Pieruccini-Faria, F., Muir-Hunter, S. W., \& Montero-Odasso, M. (2018). Do depressive symptoms affect balance in older adults with mild cognitive impairment? Results from the "gait and brain study". Experimental Gerontology, 108, 106-111.

Preacher, K. J., \& Hayes, A. F. (2008). Asymptotic and resampling strategies for assessing and comparing indirect effects in multiple mediator models. Behavior Research Methods, 40(3), 879-891.

Reis, D., \& Hoppe, A. (2015). Change in affective well-being on change in perceived job characteristics: The mediating role of hope. Journal of Occupational and Organizational Psychology, 88(1), 19-40. https://doi.org/10.1111/joop.12076.

Reker, G. T., \& Wong, P. T. P. (1988). Aging as an individual process: Toward a theory of personal meaning. In J. E. Birren \& V. L. Bengston (Eds.), Emergent theories of aging (pp. 214-246). New York, NY: Springer.

Schlegel, R. J., Hicks, J. A., King, L. A., \& Arndt, J. (2011). Feel-ing like you know who you are: Perceived true self-knowledge and meaning in life. Personality and Social Psychology Bulletin, 37(6), 745-756.

Seligman, M. E. P. (2011). Flourish: A visionary new understanding of happiness and wellbeing. New York, NY: Free Press.

Shi, M., Wang, X., Bian, Y., \& Wang, L. (2015). The mediating role of resilience in the relationship between stress and life satisfaction among Chinese medical students: A cross-sectional study. BMC Medical Education, 15(1), 16. https://doi.org/10.1186/s12909-0150297-2.

Smith, B. W., Dalen, J., Wiggins, K., Tooley, E., Christopher, P., \& Bernard, J. (2008). The brief resilience scale: Assessing the ability to bounce back. International Journal of Behavioral Medicine, 15(3), 194-200. https://doi.org/10.1080/10705500802222972.

Steger, M. F., Frazier, P., Oishi, S., \& Kaler, M. (2006). The meaning in life questionnaire: Assessing the presence of and search for meaning in life. Journal of Counseling Psychology, 53(1), 80-93. https://doi. org/10.1037/0022-0167.53.1.80.

Steger, M. F., Oishi, S., \& Kashdan, T. B. (2009a). Meaning in life across the life span: Levels and correlates of meaning in life from emerging adulthood to older adulthood. The Journal of Positive Psychology, 4(1), 43-52. https://doi.org/10.1080/17439760802303127.

Steger, M. F., Mann, J. R., Michels, P., \& Cooper, T. C. (2009b). Meaning in life, anxiety, depression, and general health among smoking cessation patients. Journal of Psychosomatic Research, 67(4), 353-358. https://doi.org/10.1016/j.jpsychores.2009.02.006.

Stevens, J. P. (2009). Applied multivariate statistics for the social sciences. New York: Routledge.

Strand, E. B., Zautra, A. J., Thoresen, M., Ødegård, S., Uhlig, T., \& Finset, A. (2006). Positive affect as a factor of resilience in the pain-Negative affect relationship in patients with rheumatoid arthritis. Journal of Psychosomatic Research, 60(5), 477-484. https:// doi.org/10.1016/j.jpsychores.2005.08.010.

Tabachnick, B. G., \& Fidell, L. S. (2013). Using multivariate statistics (6th ed.). Boston, MA: Pearson.

Tecson, K. M., Wilkinson, L. R., Smith, B., \& Ko, J. M. (2019). Association between psychological resilience and subjective wellbeing in older adults living with chronic illness. In Baylor University Medical Center Proceedings (Vol. 32, No. 4, pp. 520524). Taylor \& Francis. 
Tedeschi, R. G., \& Kilmer, R. P. (2005). Assessing strengths, resilience, and growth to guide clinical interventions. Professional Psychology: Research and Practice, 36(3), 230-237.

Tedeschi, R. G., Shakespeare-Finch, J., Taku, K., \& Calhoun, L. G. (2018). Posttraumatic growth: Theory, research, and applications. London: Routledge.

Telef, B. (2013). The scale of positive and negative experience: A validity and reliability study for adolescents. Anatolian Journal of Psychiatry, 14(1), 62. https://doi.org/10.5455/apd.36692.

Tugade, M. M., \& Fredrickson, B. L. (2004). Resilient individuals use positive emotions to bounce Back from negative emotional experiences. Journal of Personality and Social Psychology, 86(2), 320 333. https://doi.org/10.1037/0022-3514.86.2.320.

Veilleux, J. C., Lankford, N. M., Hill, M. A., Skinner, K. D., Chamberlain, K. D., Baker, D. E., \& Pollert, G. A. (2020). Affect balance predicts daily emotional experience. Personality and Individual Differences, 154, 109683.

Veronese, G., Pepe, A., Dagdukee, J., \& Yaghi, S. (2018). Social capital, affect balance, and personal wellbeing among teachers in Israel and Palestine. Teachers and Teaching, 24(8), 951-964.

Watson, D., Clark, L. A., \& Tellegen, A. (1988). Development and validation of brief measures of positive and negative affect: The PANAS scales. Journal of Personality and Social Psychology, 54(6), 1063-1070. https://doi.org/10.1037//0022-3514.54.6.1063.

Weissman, J. S., Pratt, L. A., Miller, E. A., \& Parker, J. D. (2015). Serious psychological distress among adults, United States, 2009-2013. US Department of Health and Human Services, Centers for Disease Control and Prevention, National Center for Health Statistics.

Wong, P. T. P. (1998). Meaning-centered counselling. In P. T. P. Wong \& P. S. Fry (Eds.), The human quest for meaning: A handbook of psychological research and clinical application (pp. 395-435). Mahwah, NJ: Lawrence Erlbaum Associates.

Wong, P. T. P. (2010a). What is existential positive psychology? International Journal of Existential Psychology and Psychotherapy, 3(1), 1-10. http://www.drpaulwong.com/wpcontent/uploads/2013/09/what-is-existential-positive-psychology. pdf (A shorter version was published in the encyclopedia of positive psychology edited by Lopez).

Wong, P. T. P. (2010b). The PURE strategy to create lean and excellent organizations. International Journal of Existential Psychology and Psychotherapy, 3(2), 1-21.

Wong, P. T. (2011). Positive psychology 2.0: Towards a balanced interactive model of the good life. Canadian Psychology/Psychologie Canadienne, 52(2), 69.

Wong, P. T. P. (2012a). Toward a dual-systems model of what makes life worth living. In P. T. P. Wong (Ed.), The human quest for meaning: Theories, research, and applications (2nd ed., pp. 3-22). New York, NY: Routledge.

Wong, P. T. P. (2012b). The human quest for meaning: Theories, research, and applications. New York, NY: Routledge.

Wong, P. T. P. (2016a). Meaning-seeking, self-transcendence, and wellbeing. In A. Batthyany (Ed.), Logotherapy and existential analysis: Proceedings of the Viktor Frankl Institute (Vol. 1; pp. 311322). Cham, Switzerland: Springer.

Wong, P. T. P. (2016b). Meaning centered positive group intervention. In P. Russo-Netzer, S. Schulenberg, \& A. Batthyány (Eds.), Clinical perspectives on meaning: Positive and existential psychotherapy (pp. 423-445). New York, NY: Springer.

Wong, P. T. P. (2017). Coping and stress. In A. Wenzel (Ed.), The SAGE encyclopaedia of abnormal and clinical psychology (pp. 886-890). New York, NY: Sage.

Wong, P. T. P. (2019). Second wave positive psychology's (PP 2.0) contribution to counselling psychology. Counselling Psychology Quarterly [Special Issue]. Retrieved from https://doi.org/10.1080/ 09515070.2019 .1671320 .
Wong, P. T. P., \& Bowers, V. (2018). Mature happiness and global wellbeing in difficult times. In N. R. Silton (Ed.), Scientific concepts behind happiness, kindness, and empathy in contemporary society (pp. 112-134). Hershey, PA: IGI Global.

Wong, P. T. P., \& McDonald, M. (2002). Tragic optimism and personal meaning in counselling victims of abuse. Pastoral Sciences, 20(2), 231-249.

Wong, P. T. P., \& Wong, L. C. J. (2012). A meaning-centered approach to building youth resilience. In The human quest for meaning: Theories, research, and applications (2nd ed., pp. 585-617). Routledge/Taylor \& Francis Group.

World Health Organization. (2020a). WHO timeline - COVID-19. https:/www.who.int/news-room/detail/08-04-2020-who-timeline\% 2D\%2D-covid-19

World Health Organization. (2020b). Mental health and psychosocial considerations during the COVID-19 outbreak. https://www.who. int/docs/default-source/coronaviruse/mental-health-considerations. pdf?sfvrsn $=6 \mathrm{~d} 3578$ af 2

Wu, F., Zhao, S., Yu, B., Chen, Y. M., Wang, W., Song, Z. G., ... \& Yuan, M. L. (2020). A new coronavirus associated with human respiratory disease in China. Nature, 579(7798), 265-269.

Xie, L., Zhou, J., Deng, Y., Richmond, C. J., \& Na, J. (2019). Resilience and affect balance of empty-nest older adults with mild cognitive impairment in poor rural areas of Hunan province, China. Geriatrics \& Gerontology International, 19(3), 222-227.

Yalçın, I., \& Malkoç, A. (2015). The relationship between meaning in life and subjective wellbeing: Forgiveness and Hope as mediators. Journal of Happiness Studies, 16(4), 915-929. https://doi.org/10. 1007/s10902-014-9540-5.

Yang, Y., Li, W., Zhang, Q., Zhang, L., Cheung, T., \& Xiang, Y. T. (2020). Mental health services for older adults in China during the COVID-19 outbreak. The Lancet Psychiatry, 7(4), e19. https://doi. org/10.1016/S2215-0366(20)30079-1.

Yildirim, M. (2019). Mediating role of resilience in the relationships between fear of happiness and affect balance, satisfaction with life, and flourishing. Europe's Journal of Psychology, 15(2), 183-198.

Yildirim, M., \& Belen, H. (2018). The Role of Resilience in the Relationships between Externality of Happiness and Subjective Well-being and Flourishing: A Structural Equation Model Approach. Journal of Positive School Psychology, 3(1), 62-76.

Yildirim, M., \& Arslan, G. (2020). Exploring the associations between resilience, dispositional hope, subjective wellbeing, and psychological health among adults during early stage of COVID-19. https:// doi.org/10.31234/osf.io/vpu5q.

Yıldırım, M., \& Güler, A. (2020). Factor analysis of the COVID-19 perceived risk scale: A preliminary study. Death Studies, 1-8. https://doi.org/10.1080/07481187.2020.1784311.

Yıldırım, M., \& Çelik-Tanrıverdi, F. (2020). Social Support, Resilience, and Subjective Well-being in College Students. Journal of Positive School Psychology. Retrieved from https://journalppw.com/index. $\mathrm{php} / \mathrm{JPPW} /$ article/view/229.

Yıldırım, M., Gecer, E., \& Akgül, Ö. (2020). The impacts of vulnerability, perceived risk, and fear on preventive behaviours against COVID-19. Psychology, Health \& Medicine, 1-9. https://doi.org/ 10.1080/13548506.2020.1776891.

Zhang, J., Lu, H., Zeng, H., Zhang, S., Du, Q., Jiang, T., \& Du, B. (2020). The differential psychological distress of populations affected by the COVID-19 pandemic. Brain, Behavior, and Immunity, 87, 49-50. https://doi.org/10.1016/j.bbi.2020.04.031.

Zhou, P., Yang, X. L., Wang, X. G., Hu, B., Zhang, L., Zhang, W., et al. (2020). A pneumonia outbreak associated with a new coronavirus of probable bat origin. Nature, 579(7798), 270-273.

Publisher's Note Springer Nature remains neutral with regard to jurisdictional claims in published maps and institutional affiliations. 